\title{
Spatial Organization Types of Sinoatrial Node in Dogs with Different Body Functional Reserve Levels
}

DOI: $10.17691 / \mathrm{stm} 2016.8 .2 .05$

Received December 17, 2015

T1. Vasyagina, PhD, Senior Researcher, Electron Microscopy Unit, Central Scientific Research Laboratory;

O.V. Biryukova, DSc, Professor, Department of Normal Anatomy

Nizhny Novgorod State Medical Academy, 10/1 Minin and Pozharsky Square, Nizhny Novgorod, 603005,

Russian Federation

The aim of the investigation was to reveal the spatial organization types of sinoatrial nodes in animals with different levels of body functional reserve after a single maximal exercise.

Materials and Methods. The research was carried out on 24 male mongrel dogs. Treadmill run under laboratory conditions was used to model a single maximal exercise. The exercise time was individual for each animal due to its cardio-respiratory system. A body functional reserve level was determined by the running time to refusal and the heart rate (HR) during the exercise. We studied the sinoauricular area structure using light and transmission electron microscopy. Tissue organization of myocardium was analyzed using the methods of stereology.

Results. According to HR dynamics, we distinguished two main types of functional response to maximal (excessive) exercise: type I, high HR during the running, and type II, low HR. The response types on exercise also differed in the running time and resting HR ( $p<0.05)$.

Based on stereological test findings we described the peculiarities of spatial organization of conductive and contractile myocardium in animals with different functional responses characterized by various ratios of the main tissue components. Stereological parameters in type I animals were similar to those in intact animals of a control group. Conductive and contractile myocardium in type II animals significantly differed in a relative volume of cardiomyocytes and connective tissue components from those in controls and type I animals.

Conclusion. The results of morphological studies of sinoauricular region in animals with different levels of functional body reserve compared to physiological parameters enable to predict the structural changes in the sinoatrial node area after an excess motor load.

Key words: sinoatrial node; exercise adaptation; body functional reserve; stereological analysis.

Cardiovascular system determines the body performance capability, and is the weakest unit in exercise adaptation [1-3]. For years the contractile myocardium has been an object of research of adaptation processes in clinical practice and in experiment [4-10, et al.]. Morphofunctional aspects of different motion states affecting pacemaker structures have been neglected due to an established opinion of a significant "architectural" strength of a conductive system. The difficulty in localizing the sinoatrial node (SAN) in the right atrium due to the lack of an isolation capsule and an insignificant morphological difference of a node from the surrounding myocardium is also a forcible reason why the question of SAN adaptation reserves is still open. SAN regulates the intensity of heart work depending on the body state and various environmental factors it is exposed to [11-14]. The principle of structural and functional unity suggests that any alteration of heart work is accompanied by the morphological changes of a sinoauricular area.

The adaptation to exercises is associated with a concept of functional reserves $[15,16]$. According to the organization level, there can be distinguished cell, tissue, organ and systemic reserves, as well as the reserves of the whole body. Physiological studies on urgent adaptation of the heart to motor loads [1, 17-23] evidence high variability of adaptive responses that explains the necessity for studying SAN structural peculiarities with due account of a functional body reserve level.

The aim of the investigation was to reveal the spatial organization types of sinoatrial nodes in animals with different levels of body functional reserve after a single maximal exercise.

Materials and Methods. The experiments were carried out on 24 male mongrel dogs weighing 10-27 kg. The researches were performed in full agreement with the ethic principles established by European Convention for the Protection of Vertebrate Animals used for Experimental and other Scientific Purposes (adopted in 18.03.1986 in Strasburg and approved in 15.06.2006 in Strasburg) and approved by the Ethics Committee of Nizhny Novgorod State Medical Academy.

Group 1 animals $(n=12)$ received a single motor load: treadmill run at a speed of $15 \mathrm{~km} / \mathrm{h}$ till voluntary refusal, group $2(n=12)$ served as control.

For contacts: Tatiana I. Vasyagina, e-mail: tvasyagina@yandex.ru 
Heart rate $(\mathrm{HR})$ was recorded before an exercise, at start, once a minute during the exercise, and postexercise, using a 4-channel electroencephalograph EEG-1 (Russia) calculating a mean value during a running exercise. A running time was recorded to assess the body performance capability. An adaptation reserve was estimated by HR growth during and after the exercise, it being expressed in percentage from an individual background value of the parameter.

After physiological studies the animals were sacrificed, they being subject to the humane treatment rules, and anesthetized by sodium barbiturate $(30 \mathrm{mg} /$ $\mathrm{kg}$, intravenously). The heart was isolated in automatic breathing. The tissue samples, about $1 \mathrm{~cm}^{2}$ in size, including the sinoauricular area were fixed in $2.5 \%$ glutaraldehyde in $0.1 \mathrm{M}$ phosphate buffer followed by their fixation in $1 \%$ osmium tetroxide solution. The material was textured and embedded in epon. The conductive myocardium was identified on series of semifine sections cresyl violet and basic fuchsin stained [24]. The microsections were photographed using DMLS microscope (Leica, Microsystems, Germany) and a small color camera (CCD-matrix) in the range of working magnifications from 10 to 100 . Ultrathin myocardial sections were contrasted by lead citrate, and studied under an electron microscope Morgagni 268D (FEI, USA), $\times 5,000-15,000$.

To assess the spatial organization of a sinoauricular area we used stereological analysis. Relative volume of the main tissue components in conductive and contractile myocardium was calculated on electron micrographs at 5,000 s magnification using an ImageJ program.

The findings were statistically processed using Statistica 10.0. The two groups were compared by
Student t-test. The differences were considered significant if $p<0.05$.

Results. The running time of dogs till voluntary refusal varied in the range from 30 to $150 \mathrm{~min}$. Individual HR range during the run was from 158 to $261 \mathrm{bpm}$. By running time and HR dynamics there were distinguished two main types of functional response on maximal (excessive) exercise: type I $(n=6)$, with high HR range during the running; and type II $(n=6)$, with low HR range during the exercise (Figure 1). Starting HR in animals with different types of functional responses on exercise and HR growth during running had significant intertypic differences. It should be noted that mean HR during the exercise and post-exercise HR growth had no significant differences in dogs with different functional response types.

A sinoauricular area of the heart is located in a subepicardial layer of the right atrium, and unites SAN and boundary contractile myocardium. This area in a dog is characterized by the presence of a large artery of muscular type (Figure 2).

A stereological test revealed the post-exercise increase of the relative volume of both conductive, and contractile cardiomyocytes in dogs (See the Table). It should be emphasized that significant changes compared to the controls were found in type II response animals only.

A significant increase of the relative parenchyma volume was associated with marked intracellular edema of cardiomyocytes (Figure 3). Both groups of animals demonstrated unidirectional qualitative ultrastructural changes of mitochondria: polymorphism, local or total fragmentation of cristae, matrix clarification or homogenization of organelle content. Primary and secondary lysosomes being in close contact with

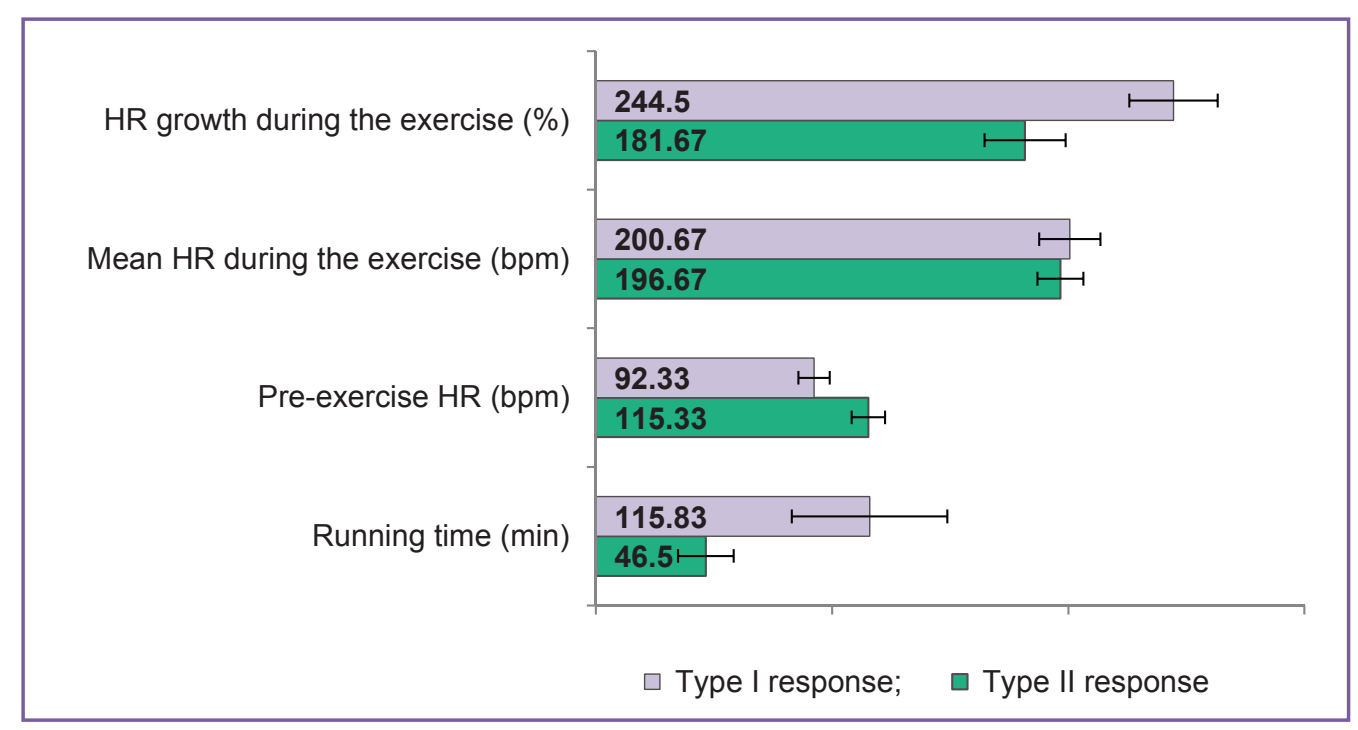

Figure 1. Physiological parameters of dogs with different functional reserve level under a single maximal exercise: type I is high functional reserve level; type II is low functional reserve level 


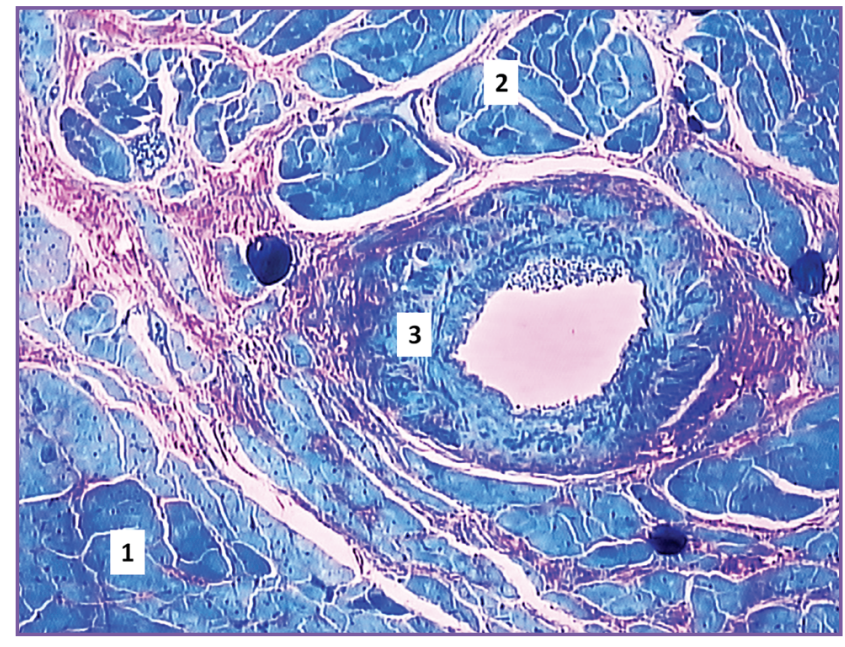

Figure 2. The sinoauricular area of an intact dog's heart; a semi-thin section; cresyl violet and basic fuchsin staining: 1 - conductive myocardium; 2 - contractile myocardium; 3 - the artery of a sinoatrial node; $\times 4$

mitochondria were found more frequently in dogs under study than in controls. The nuclei appeared to have increased heterochromatin parts accompanied by the increased invagination of a nuclear membrane. Vesiculation and disarrangement of sarcoplasmic reticulum elements were sometimes combined with local lysis of myofibrils and low electron density of sarcoplasm. Intercalated disks preserved their standard structure. The mentioned signs of the response were found in all types of cardiomyocytes. Most secretory and contractile

Relative volume (\%) of tissue components of a sinoauricular cardiac area of dogs after a single maximal exercise $(\mathrm{M} \pm \mathrm{m})$

\begin{tabular}{|lcccc}
\hline \multicolumn{1}{c}{$\begin{array}{c}\text { Tissue } \\
\text { components }\end{array}$} & $\begin{array}{c}\text { Control } \\
(\mathrm{n}=12)\end{array}$ & $\begin{array}{c}\text { Experiment } \\
\text { Complete sample } \\
(\mathrm{n}=12)\end{array}$ & $\begin{array}{c}\text { Type I response } \\
(\mathrm{n}=6)\end{array}$ & $\begin{array}{c}\text { Type } \boldsymbol{I I} \text { response } \\
(\mathrm{n}=6)\end{array}$ \\
\hline Cardiomyocytes & $59.02 \pm 1.81$ & $62.49 \pm 2.07$ & $57.36 \pm 1.18$ & $67.60 \pm 2.64^{*}$ \\
\hline Connective tissue & $33.20 \pm 1.88$ & $28.14 \pm 2.39$ & $34.35 \pm 1.28$ & $21.93 \pm 2.85^{* *}$ \\
\hline Capillaries & $5.30 \pm 0.56$ & $5.89 \pm 0.59$ & $4.92 \pm 0.70$ & $6.87 \pm 0.80$ \\
\hline Nerve elements & $2.48 \pm 0.36$ & $3.48 \pm 0.28$ & $3.37 \pm 0.33$ & $3.60 \pm 0.48$ \\
\hline \multicolumn{5}{c}{ Contractile myocardium } \\
\hline Cardiomyocytes & $80.78 \pm 0.71$ & $82.04 \pm 1.19$ & $79.52 \pm 1.42$ & $84.57 \pm 1.29^{*}$ \\
\hline Connective tissue & $13.91 \pm 0.65$ & $11.93 \pm 1.01$ & $14.03 \pm 1.30$ & $9.84 \pm 1.02^{* *}$ \\
\hline Capillaries & $3.58 \pm 0.21$ & $4.25 \pm 0.30$ & $4.42 \pm 0.40$ & $4.07 \pm 0.49$ \\
\hline Nerve elements & $1.73 \pm 0.20$ & $1.78 \pm 0.27$ & $2.03 \pm 0.45$ & $1.52 \pm 0.32$ \\
\hline
\end{tabular}

$\mathrm{N}$ o t e. Significant difference of values in relation to those of control: * $p<0.05$; ${ }^{* *} p<0.01$.

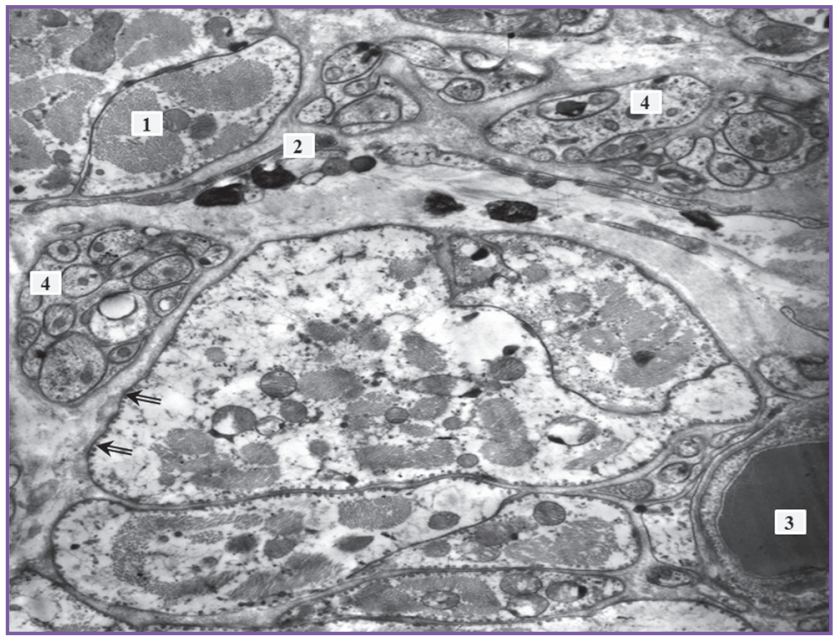

Figure 3. The sinoauricular area ultrastructure of the dog's heart with low functional reserve after a single maximal exercise; 1 - cardiomyocyte; 2 - a mast cell; 3 - hemocapillar; 4 - a bundle of nonmyelinated nerve fibers. Arrows indicate the increase of pinocytic activity of sarcolemma; $\times 5,000$

cardiomyocytes were in a state of hyperfunction. However, the basic amount of secretory granules was localized in intermyofibrillar and subsarcolemmal areas of a cell. Membrane structures of Golgi complex were found in perinuclear area, as well as under sarcolemma.

Qualitative studies of capillary ultrastructure revealed significant reorganization of a microcirculatory bloodstream. The majority of hemocapillaries were active, with a wide lumen, and intensive pinocytosis. Reserve capillaries were very rare. Some endotheliocytes were edematous and exhibited low pinocytic activity. Such capillaries were primarily found in contractile myocardium of animals with low functional reserve.

Relative capillary volume in a sinoauricular area increased (See the Table). Microvessels in the animals with type II functional response on exercise had a larger relative volume than the type I animals and controls.

The connective tissue of a sinoauricular area after excessive load suffered changes as well. Macrophages containing heterogeneous inclusions were found more frequently in animals under study compared to the controls. There was also the degranulation of mast cells (See Figure 3). Stereological analysis revealed the reduction of relative total volume of cells, fibers, and the basic structure of connective tissue in both conductive and contractile 
myocardium. The dogs with low functional cardiac reserve appeared to differ significantly from the controls.

The post-exercise ultrastructure of nerve elements in the cardiac area under study differed significantly from that in the norm. In neurite-glial complexes of small and large diameter there was swelling of glioand neuroplasm of different intensity accompanied by the gliocyte mitochondrial cristal fragmentation. Not infrequently there were found complexes with neuroplasm of high electron density due to the increase of neurotubule concentration, and simultaneous neurofiaments combined with vacuoles in neuroplasm. Regional differences in the response intensity were revealed only by the means of a stereological analysis. The studies showed the relative volume of nerve structures to grow mainly in the contractile myocardium (See the Table).

Discussion. In general, the revealed morphological changes in SAN are similar to the described in literature data on the contractile myocardial response on a single maximal exercise [25]. Our researches are confirmed by the findings of other authors suggesting that the main factors influencing the myocardial structure in exercise are hypoxia combined with lactic acidosis [21, 26, 27]. In addition, the obtained data shows SAN structure of the heart in dogs with different functional reserve level has its evident differences: after running to the refusal, the myocardium of a sinoauricular area in animals with high functional reserve suffers less than in those with a low functional reserve level. On this base we can conclude about low cardiac structural reserves in animals with type II functional response at an organ, tissue, cellular and subcellular level. We suppose that higher values of relative cardiomyocyte volume in such dogs can be explained by higher values of the parameter at initial state. Another consideration is that a sharp intensity increase of rhythmogenic and contractile cardiac function under exercise conditions resulting in an additional increase in relative cardiomyocyte volume of conductive and contractile myocardium. At that moment a water fraction is distributed between different tissue components. A passive increase of the relative volume of cardiomyocytes is accompanied by the reduced relative volume of connective tissue. A part of water fraction under this load is likely to change into cardiac myocytes, endotheliocytes and neurite-glial complexes. Similar changes in myocardium and motor neurons of spinal cord in post-exercise infant rats were described by Gritsyuk [28]. A large relative volume of parenchyma at initial state with subsequent water-salt homeostasis failure during running can result in significant imbalance in volume relations of the main tissue components and, therefore, more intensive changes in the ultrastructure of parenchymal and stromal cells.

Thus, the comparison of morphological study findings with physiological parameters enables to predict individual typological characteristics of structural rearrangements, which occur in a sinoatrial node after an excessive motor exercise.

Conclusion. A complex study of animals with different performance capability levels of the body functional reserve enables to distinguish the types of a structural organization of a sinoatrial node and contractile myocardium of the right atrium. These data are of great importance and should be taken into consideration in sports medicine when using tolerance tests and determining a performance level of sportsmen.

Study Funding and Conflicts of Interest. The study was not funded by any sources, and the authors have no conflicts of interest related to the present study.

\section{References}

1. Perrino C., Gargiulo G., Pironti G., Franzone A., Scudiero L., De Laurentis M., Magliulo F., llardi F., Carotenuto G., Schiattarella G.G., Esposito G. Cardiovascular effects of treadmill exercise in physiological and pathological preclinical settings. Am J Physiol Heart Circ Physiol 2011; 300(6): H1983-H1989, http://dx.doi.org/10.1152/ ajpheart.00784.2010.

2. Wilson M.G., Ellison G.M., Cable N.T. Basic science behind the cardiovascular benefits of exercise. Heart 2015; 101(10): 758-765, http://dx.doi.org/10.1136/ heartjnl-2014-306596.

3. Zilinski J.L., Contursi M.E., Isaacs S.K., Deluca J.R., Lewis G.D., Weiner R.B., Hutter A.M. Jr., d'Hemecourt P.A., Troyanos C., Dyer K.S., Baggish A.L. Myocardial adaptations to recreational marathon training among middle-aged men. Circ Cardiovasc Imaging 2015; 8(2): e002487, http://dx.doi. org/10.1161/CIRCIMAGING.114.002487.

4. Stepien R.L., Hinchcliff K.W., Constable P.D., Olson J. Effect of endurance training on cardiac morphology in Alaskan sled dogs. J Appl Physiol 1998; 85(4): 1368-1375.

5. D'Andrea A., Caso P., Sarubbi B., Limongelli G., Liccardo B., Cice G., D'Andrea L., Scherillo M., Cotrufo M., Calabrò R. Right ventricular myocardial adaptation to different training protocols in top-level athletes. Echocardiography 2003; 20(4): 329-336, http://dx.doi.org/10.1046/j.15408175.2003.03038.x.

6. Kukielka M., Seals D.R., Billman G.E. Cardiac vagal modulation of heart rate during prolonged submaximal exercise in animals with healed myocardial infarctions: effects of training. Am J Physiol Heart Circ Physiol 2006; 290(4): H1680H1685, http://dx.doi.org/10.1152/ajpheart.01034.2005.

7. Ferasin L., Marcora S. Reliability of an incremental exercise test to evaluate acute blood lactate, heart rate and body temperature responses in Labrador retrievers. J Comp Physiol B 2009; 179(7): 839-845, http://dx.doi.org/10.1007/ s00360-009-0367-z.

8. Kemi O.J., Wisløff U. Mechanisms of exercise-induced improvements in the contractile apparatus of the mammalian myocardium. Acta Physiol (Oxf) 2010; 199(4): 425-439, http:// dx.doi.org/10.1111/j.1748-1716.2010.02132.x.

9. La Gerche A., Burns A.T., Mooney D.J., Inder W.J., Taylor A.J., Bogaert J., Macisaac A.I., Heidbüchel H., Prior D.L. Exercise-induced right ventricular dysfunction and structural remodelling in endurance athletes. Eur Heart $J$ 2012; 33(8): 998-1006, http://dx.doi.org/10.1093/eurheartj/ehr397. 
10. Carneiro-Júnior M.A., Prímola-Gomes T.N., QuintãoJúnior J.F., Drummond L.R., Lavorato V.N., Drummond F.R., Felix L.B., Oliveira E.M., Cruz J.S., Natali A.J., Mill J.G. Regional effects of low-intensity endurance training on structural and mechanical properties of rat ventricular myocytes. J Appl Physiol 2013; 115(1): 107-115, http://dx.doi. org/10.1152/japplphysiol.00041.2013.

11. Kim K.S., Ardell J.L., Randall W.C., Pomeroy G., Calderwood D. Cardiac responses to exercise in the dog before and after destruction of the sinoatrial node. Eur J Appl Physiol Occup Physiol 1986; 55(3): 253-258, http://dx.doi. org/10.1007/bf02343796.

12. Stein R., Medeiros C.M., Rosito G.A., Zimerman L.I., Ribeiro J.P. Intrinsic sinus and atrioventricular node electrophysiologic adaptations in endurance athletes. $J \mathrm{Am}$ Coll Cardiol 2002; 39(6): 1033-1038, http://dx.doi.org/10.1016/ s0735-1097(02)01722-9.

13. Baldesberger S., Bauersfeld U., Candinas R., Seifert B., Zuber M., Ritter M., Jenni R., Oechslin E., Luthi P., Scharf C., Marti B., Attenhofer Jost C.H. Sinus node disease and arrhythmias in the long-term follow-up of former professional cyclists. Eur Heart J 2008; 29(1): 71-78, http://dx.doi. org/10.1093/eurheartj/ehm555.

14. Monfredi O., Dobrzynski H., Mondal T., Boyett M.R., Morris G.M. The anatomy and physiology of the sinoatrial node - a contemporary review. Pacing Clin Electrophysiol 2010; 33(11): 1392-1406, http://dx.doi.org/10.1111/j.15408159.2010.02838.x.

15. Radzievskiy A., Priymakov A., Oleshko V., Yashanin N. About accumulation, expenditure and redistribution of functional reserves in a human body. Nauka $v$ olimpiyskom sporte 2002; 3-4: 110-119.

16. Davidenko D.N. A problem of sportsman's body adaptation reserves. Uchenye zapiski universiteta im. P.F. Lesgafta 2005; 18: 15-24.

17. Lee M.C., Wood R.H., Welsch M.A. Influence of shortterm endurance exercise training on heart rate variability. Med Sci Sports Exerc 2003; 35(6): 961-969, http://dx.doi. org/10.1249/01.mss.0000069410.56710.da.

18. Ostojic S.M., Stojanovic M.D., Calleja-Gonzalez J. Ultra short-term heart rate recovery after maximal exercise: relations to aerobic power in sportsmen. Chin J Physiol 2011; 54(2): 105-110, http://dx.doi.org/10.4077/CJP.2011.AMM018.

19. Rathore N.S., Moolchandani A., Sareen M., Rajput D.S. Effect of treadmill exercise on some physiological and hematological parameters in German Shepherd dogs. Veterinary Practitioner 2011; 12(1): 38-39.

20. Neves F.J., Carvalho A.C., Rocha N.G., Silva B.M.,
Sales A.R., de Castro R.R., Rocha J.D., Thomaz T.G., Nóbrega A.C. Hemodynamic mechanisms of the attenuated blood pressure response to mental stress after a single bout of maximal dynamic exercise in healthy subjects. Braz J Med Biol Res 2012; 45(7): 610-616, http://dx.doi.org/10.1590/S0100879X2012007500083.

21. Piccione G., Casella S., Panzera M., Giannetto C., Fazio $F$. Effect of moderate treadmill exercise on some physiological parameters in untrained Beagle dogs. Exp Anim 2012; 61(5): 511-515, http://doi.org/10.1538/expanim.61.511.

22. D'Ascenzi F., Pelliccia A., Natali B.M., Zacà V., Cameli M., Alvino F., Malandrino A., Palmitesta P., Zorzi A., Corrado D., Bonifazi M., Mondillo S. Morphological and functional adaptation of left and right atria induced by training in highly trained female athletes. Circ Cardiovasc Imaging 2014; 7(2): 222-229, http://doi.org/10.1161/ CIRCIMAGING.113.001345.

23. Biryukova O.V., Baranov N.A., Vasyagina T.I. Adaptive response of the heart and peripheral vasculature on single physical exercises in experiment. Sovremennye tehnologii $v$ medicine 2015; 7(2): 55-61, http://dx.doi.org/10.17691/ stm2015.7.2.07.

24. Vasyagina T.I., Edeleva N.K., Biryukov Yu.V. Cresyl violet and basic fuchsin staining technique for semi-thin sections of large areas for light microscopy. Morfologiya 2011; 140(5): 74 .

25. Silkin Yu.R. Strukturno-funktsional'naya organizatsiya miokarda levogo zheludochka pri adaptatsii organizma k dvigatel'nym nagruzkam. Avtoref. dis. ... dokt. med. nauk [Structural and functional left ventricular myocardial organization in body adaptation to motor loads. DSc Thesis]. Moscow; 2000.

26. Vysochin Yu.V., Denisenko Yu.P. Modern concepts of physiological mechanisms of urgent sportsmen's adaptation to exercises. Teoriya i praktika fizicheskoy kul'tury 2002; 7: 2-6.

27. Kornyakova V.V., Konway V.D. The role of infringement of metabolism purines in damage of cardiomyocytes in rats under physical activities. Omskiy nauchnyy vestnik 2012; 1(108): 96-99.

28. Gritsyuk T.V. Morfofunktsional'nye izmeneniya $v$ dvigatel'nykh neyronakh spinnogo mozga, serdechnoy $i$ skeletnoy myshtsy nepolovozrelykh belykh krys pri vozdeystvii fizicheskikh nagruzok i $v$ usloviyakh primeneniya fitopreparatov. Avtoref. dis. ... kand. med. nauk [Morphofunctional changes in motor neurons of spinal cord, cardiac and skeletal muscles of immature white mice when exposed to exercises and under phytopreparation therapy. PhD Thesis]. Saint Petesburg; 1994. 